\title{
Alasdair Maclntyre e a Filosofia do Esporte: uma discussão comparativa sobre o conceito de prática
}

\author{
Alasdair MacIntyre and the Philosophy of Sport: a comparative discussion on the concept \\ of practice

\section{Alasdair MacIntyre y la Filosofía del Deporte: una discusión comparada sobre el concepto de práctica}

Paulo Augusto Boccatia (D) Samuel Ribeiro dos Santos Neto ${ }^{\text {b* }}$ (D)

Palavras-chave:

Filosofia do Esporte;

Práticas sociais;

Práticas corporais;

Educação Física.

\begin{abstract}
RESUMO
$\mathrm{O}$ artigo teve por objetivo apresentar o conceito de práticas sociais do filósofo Alasdair Maclntyre, a partir de seus usos na Filosofia do Esporte, e compará-lo com o conceito de práticas corporais mobilizado na literatura brasileira do campo da Educação Física. A discussão foi realizada a partir de uma revisão narrativa de ambos os conceitos, buscando contextualizar seus percursos epistemológicos, apropriações e possíveis fragilidades e potencialidades. Foi possível constatar que o conceito de práticas de Maclntyre é dotado de estabilidade e possibilita a investigação estruturada de questões específicas dos esportes, mas possui menor amplitude de significantes comparado ao conceito de práticas corporais.
\end{abstract}

\section{Keywords:}

Philosophy of Sports;

Social practices;

Bodily practices; Physical Education.

\begin{abstract}
The article aimed to present the concept of social practices of the philosopher Alasdair Maclntyre, based on its uses in the Philosophy of Sport, and compare it with the concept of bodily practices mobilized in the Brazilian literature in the field of Physical Education. The discussion was carried out from a narrative review of both concepts, seeking to contextualize their epistemological paths, appropriations and possible weaknesses and potentialities. It was possible to verify that Maclntyre's concept of practices is endowed with stability and allows for a structured investigation of specific sports issues, but it has a smaller amplitude of signifiers when compared to the concept of bodily practices.
\end{abstract}

Palabras-clave:

\section{RESUMEN}

Filosofía del Deporte; Prácticas sociales; Prácticas corporales; Educación Física.
El artículo tuvo como objetivo presentar el concepto de prácticas sociales del filósofo Alasdair Maclntyre, basado en sus usos en la Filosofía del Deporte, y compararlo con el concepto de prácticas corporales movilizado en la literatura brasileña en el campo de la Educación Física. La discusión se realizó a partir de una revisión narrativa de ambos conceptos, buscando contextualizar sus trayectorias epistemológicas, apropiaciones y posibles debilidades y potencialidades. Se pudo verificar que el concepto de prácticas de MacIntyre está dotado de estabilidad y permite una investigación estructurada de cuestiones deportivas específicas, pero tiene un rango de significantes menor en comparación con el concepto de prácticas corporales.

aUniversidade Estadual de Campinas, Faculdade de Educação Física, Programa de Pós-graduação em Educação Física. Campinas, SP, Brasil bUniversidade Estadual de Campinas, Faculdade de Educação, Programa de Pós-graduação em Educação. Campinas, SP, Brasil

\footnotetext{
*Autor correspondente:

Samuel Ribeiro dos Santos Neto

E-mail: samuelrs.unicamp@gmail.com
} 


\section{INTRODUÇÃO}

A palavra prática é cara à Educação Física, área de atuação e de produção científica caracterizada pela reflexividade sobre suas intervenções profissionais que remetem ao corpo, à saúde e ao movimento humano. Sendo um termo passível de múltiplas definições e apropriações, no contexto de um campo marcado pela fragmentação disciplinar (Betti, 1996, 2005) e pela diversidade de pesquisas, é importante que sua mobilização na literatura acadêmica seja feita de modo preciso e explícito, visto que diferentes sentidos de uma mesma palavra podem apontar para concepções políticas e epistemológicas diversas.

Dentro da Filosofia do Esporte, um uso frequente do termo prática tem sido feito a partir do conceito desenvolvido pelo filósofo contemporâneo Alasdair Maclntyre, uso este ainda incipiente na literatura nacional (Boccati, 2020).

A Filosofia do Esporte visa, através de bases epistemológicas da Filosofia, apresentar exames reflexivos sobre a natureza do esporte e questões relacionadas. Seu estudo sistêmico é relativamente novo a nível global, iniciando nos anos 1970 e passando por diversas fases com diferentes abordagens, sendo que nos anos 1990 o trabalho de Maclntyre em Depois da Virtude passou a exercer grande influência na área (Devine e Lopez Frías, 2020).

Nesse sentido, o objetivo deste artigo é apresentar o conceito de práticas segundo Maclntyre em comparação com o conceito de práticas corporais, desenvolvido por pesquisadores brasileiros da Educação Física e presente de forma heterogênea em um grande número de artigos. Por meio de uma revisão narrativa, pretende-se aqui apresentar os conceitos e suas trajetórias epistemológicas, elencando potencialidades e fragilidades, bem como diferenciá-los e compará-los.

Ao apresentar e comparar dois conceitos na área - um relativamente novo no Brasil e restrito à Filosofia do Esporte, outro já presente em diálogos mais amplos da Educação Física nas últimas décadas -, espera-se contribuir pontualmente com os debates epistemológicos da Educação Física, instrumentalizando autores e também profissionais para que reflitam sobre sua própria atuação.

Evidentemente, tratam-se de conceitos distintos em muitos sentidos, mas que compartilham um espaço dialógico comum em uma mesma paisagem epistemológica da Educação Física. Sendo dotado de maior enraizamento e tradição nessa paisagem, o termo práticas corporais impõe a necessidade de ser contextualizado antes que se passe ao exame das práticas para MacIntyre.

\section{O CONCEITO DE PRÁTICAS CORPORAIS}

Nas últimas duas décadas, houve um esforço em conceituar o que se compreende por práticas corporais, termo utilizado desde os anos 1990 em publicações da Educação Física para se referir aos seus objetos de pesquisa e de intervenção profissional, como esportes, ginásticas, lutas, danças, jogos e brincadeiras, entre outros.

A busca por precisão conceitual faz parte do amadurecimento de qualquer campo científico. No caso da Educação Física brasileira, área acadêmica historicamente recente e de produção bastante pulverizada entre diferentes saberes (ciências biológicas, humanas e exatas), há a necessidade de produzir consensos mínimos em torno dos conceitos mobilizados (Lazzarotti et al., 2010). Não é acidental, nesse sentido, que isso se opere em referência às manifestações corporais que resultam da intervenção profissional da Educação Física ou que por ela possam ser apreendidas e interpretadas.

Conforme Betti $(1996,2005)$, o dilema teoriaprática é constitutivo do campo chamado Educação Física. Embora a área tenha sido vinculada a diferentes interesses e saberes em suas manifestações no século XX (como o militarismo, a medicina e o esporte), Betti (1996) destaca, em diálogo com autores como Valter Bracht e Hugo Lovisolo, que o ponto comum da Educação Física funda-se na formação orientada para a intervenção prática, a partir disso se desdobrando boa parte de sua produção enquanto área acadêmica tardia.

Assim, não é menor a preocupação com a definição dos objetos dessa intervenção, visto que ela tem relação com a própria conformação da atividade profissional e seus impactos na realidade social. Não se trata de mera questão terminológica.

De acordo com Silva (2014) e Silva et al. (2014), há uma tripla dimensão ligada à ideia de práticas corporais: como concepção teórica, como conteúdos da atividade profissional e também como um movimento social mais amplo, que repercute nas políticas de lazer, educação e saúde. Em relação à última, de fato, o termo tem aparecido em documentos oficiais, especialmente após os anos 2000, como na Política Nacional de Promoção da Saúde de 2006 (Lazzarotti et al, 2010).

Em linhas gerais, a noção de práticas corporais é herdeira dos debates construídos pela Educação Física no âmbito das ciências humanas, em que uma das manifestações mais marcantes é o conceito de cultura corporal da obra Metodologia de Ensino de Educação Física (Coletivo de Autores, 1992), que situa as diferentes práticas do campo (jogo, esporte, capoeira, ginástica, dança, etc) na perspectiva da cultura e da linguagem. Práticas, portanto, que não se resumem às dimensões técnicas e anatomofisiológicas, mas compreendem também as dimensões subjetivas, individuais e coletivas.

De acordo com Silva e Damiani (2005, p. 24) em uma sistematização inicial do termo, as práticas corporais possuem "enraizamento cultural" e são profundamente conectadas aos diversos aspectos da vida humana. Não se trata só da escolha de um termo genérico que abarque uma multiplicidade de expressões corporais, mas também da produção de um enquadramento teórico 
que oriente e dispute a intervenção profissional e o olhar científico sobre essas expressões. Isso exige uma abordagem interdisciplinar.

Em nossa compreensão, as práticas corporais devem ser tratadas pelas ciências humanas e sociais, pela arte, pela filosofia e pelos saberes populares, sem desprezar as ciências biológicas, dado que esta dimensão é constituinte fundamental do humano, tomando-se seus indicadores como parte do processo ativo de auto-organização subjacente à vida. (Silva e Damiani, 2005, p. 21).

O olhar ampliado e centrado na cultura serve à demarcação do termo em perspectiva ontológica, opondo práticas corporais ao conceito de atividade física, amparado principalmente nas ciências biológicas, que é bastante difundido e dá centralidade às adaptações orgânicas e aos gastos energéticos gerados por estímulos biomecânicos. Ontologicamente, o conceito de prática corporal afirma-se na negação daquilo que não é ou que não se quer que ele seja (Silva et al, 2014), especificamente, algo ligado a uma perspectiva biologicista, funcionalista e instrumental.

Sem recusar os saberes biológicos, mas retirando deles o monopólio explicativo sobre o corpo, o conceito de práticas corporais representa um afastamento promovido pelas ciências humanas dentro da Educação Física em relação ao lugar historicamente produzido para o corpo na modernidade, principalmente no século XX. Nesses contextos, as intervenções práticas foram orientadas ao controle, à disciplina e à racionalização do corpo e de suas expressões.

Tal perspectiva instrumental, que opera sobre um corpo passivo, a-histórico, sem subjetividade e separado das demais dimensões da vida, funda-se na ciência moderna e remete, como ensaia Silva (2014), a um desdobramento histórico de longa duração do materialismo estoico da Antiguidade. Ou seja, parte de uma dimensão física do corpo que é, sobretudo, material, bastante distinta da ideia de physis da tradição helênica e apartada das dimensões espirituais e mentais da vida.

Em sentido diverso, o conceito de práticas corporais parte - e também espera produzir ou reforçar - de outra perspectiva de corpo, criativa e diversa, sem generalizações ou pretensões universais, situada na cultura e na história. Dentro das pesquisas históricas na Educação Física, o conceito ajudou a produzir novos objetos e reconhecer outras lógicas que não as hegemônicas ao longo dos séculos XIX e XX, a saber, a ginástica e principalmente o esporte, que "invadiu" ou "domesticou" outras práticas com sua racionalidade, valores e espacialidades (Soares, 2005).

Assim, falar em práticas corporais permitiu à área olhar com profundidade para manifestações como artes circenses, práticas tradicionais indígenas, capoeira, artes corporais vindas da Ásia, entre outras. Mais: possibilitou que isso fosse feito a partir dos referenciais próprios de cada contexto cultural, sem meramente importar códigos do mundo esportivo ou dos princípios do treinamento para explicar as expressões corporais.

Tal pluralidade é vislumbrada mesmo nos trabalhos que mobilizam a categoria práticas corporais sem defini-la de modo preciso, que são a maioria. A revisão de Lazzarotti et al. (2010) apontou que, em tais casos, o termo era frequentemente adjetivado (práticas corporais escolares, indígenas, orientais, alternativas, etc). Ou, ainda, tratado como sinônimo de cultura corporal ou de seus conteúdos e, em alguns casos, apresentado, em aparente contradição, como sinônimo de atividade física.

As constatações demonstram, por um lado, a amplitude do conceito, que permite abarcar diferentes expressões, inclusive aquela à qual se opõe ontologicamente (seja pelo uso impreciso que o equipara às atividades físicas, ou por sua capacidade de abarcar uma categoria mais restrita; afinal, toda atividade física não deixa de ser também uma prática corporal). Por outro, demonstram um uso empírico e pouco preciso do termo, sobretudo em publicações anteriores à ampliação de seu debate conceitual nos anos 2000 e 2010.

Apesar disso, Silva (2014) destaca que, conforme o uso do termo se expandiu, produziu-se também um consenso mínimo e tácito entre a comunidade científica que com ele dialoga. O consenso, argumenta, é um indicativo do amadurecimento para a consolidação de práticas corporais enquanto conceito. Em sua definição,

Em síntese, pode-se dizer que as práticas corporais são fenômenos que se mostram, prioritariamente, ao nível corporal, constituindo-se em manifestações culturais, tais como os jogos, as danças, as ginásticas, os esportes, as artes marciais, as acrobacias, entre outras. Esses fenômenos culturais que se expressam fortemente no nível corporal e que, em geral, ocorrem no tempo livre ou disponível, com importante impacto orgânico. São constituintes da corporalidade humana e podem ser compreendidos como forma de linguagem com profundo enraizamento corporal que, por vezes, escapam ao domínio do consciente e da racionalização, o que lhes permite uma qualidade de experiências muito diferenciada de outras atividades cotidianas. (Silva, 2014, p. 18).

As práticas corporais também são constituídas por técnicas e saberes historicamente situados e por interações sociais que lhes dão significado coletivo. Pressupõem determinados objetos e espaços para a sua realização e costumam apresentar um componente lúdico (Lazzarotti et al., 2010; Silva et al., 2014). Trata-se de um conceito que se pretende amplo e pouco específico mas que, ao mesmo tempo, exige múltiplas descrições e argumentos para garantir sua mínima estabilização.

Soma-se a isso a polifonia do conceito, expressa no tratamento interdisciplinar que o fundamenta, na pluralidade de objetos que ele pode conter (os significantes) e, apesar do relativo consenso, em suas 
diversificadas apropriações, com maior ou menor grau de precisão.

Segundo Lazzarotti et al. (2010), a dificuldade de fechar conceitos é constitutiva das ciências humanas, que exigem dinamismo e transformam constantemente o significado dos termos. Em Silva (2014) essa perspectiva é reforçada: quando se fala do conceito práticas corporais, não se tem a pretensão de estabilizá-lo ou limpá-lo das contradições. A autora entende que o conceito é vinculado à realidade social e que, conforme ela se transforma, o põe continuamente em teste e impõe ajustes.

Por essas razões, Silva (2014) destaca que pensar as práticas corporais implica superar o enfoque meramente epistemológico, sendo necessária uma perspectiva ontológica, gnosiológica e também política. $O$ conceito é um operador da realidade, tanto refletindo como reposicionando relações de poder, como evidencia sua presença em políticas públicas.

É possível afirmar que o conceito, ainda que de forma heterogênea e por vezes pouco precisa, tem sido amplamente utilizado por pesquisadores da Educação Física, particularmente os das ciências humanas. O consenso mínimo permitiu que características básicas das práticas corporais pudessem ser reconhecidas. Antes de fragilidades, as instabilidades conceituais existentes são o preço a pagar pela amplitude de significantes do conceito e pelo território interdisciplinar no qual ele circula.

Por um lado, talvez a pacificação conceitual não seja o caminho a se seguir, mas sim a busca contínua por consensos mínimos, permitindo que o termo ajude a Educação Física a pensar e repensar a sua intervenção (Lazzarotti et al., 2010). Por outro, é possível argumentar que a utilização do mesmo termo com significados diferentes pode dificultar o debate de questões que o requerem enquanto conceito, uma vez que, se o princípio de identidade não for respeitado do ponto de vista lógico formal, a utilização do termo nas premissas argumentativas pode levar a conclusões diferentes dependendo daquilo que se entende do conceito requerido.

Portanto, com conclusões diferentes a partir das mesmas premissas, devido à falta do princípio de identidade dos termos, o diálogo entre os interlocutores pode ficar prejudicado com a ilusão de uma discussão estéril das conclusões, uma vez que o problema real encontra-se no entendimento dos termos, que deveriam ser esclarecidos antes das conclusões a que possam servir de base.

Tomando em conta as considerações já tecidas por Lazzarotti et al. (2010), Silva (2014) e Silva et al. (2014), nota-se a importância de que o entendimento dos termos utilizados nos argumentos esteja também estabilizado, ou, caso haja alteração de significado em decorrência da necessidade de adequação, que esta seja explicitamente mencionada.
Tendo em vista as características do conceito, será feita a seguir, a título de comparação, uma apresentação do pensamento de MacIntyre, evidenciando como o termo prática é usado na Filosofia do Esporte e alguns dos desdobramentos que o pensamento do autor suscitou no campo.

\section{A FILOSOFIA DO ESPORTE E A PRÁTICA SEGUNDO MACINTYRE}

Alasdair MacIntyre é um filósofo contemporâneo que, além da influência na Filosofia do Esporte, é conhecido pelas contribuições para a Filosofia Moral e Política. Sua abordagem filosófica inclui, primeiramente, uma história da filosofia e da tradição ética, para então propor uma teoria das virtudes ${ }^{1}$.

Partindo de inspirações aristotélicas, Maclntyre (2001) afirma que a virtude contribui para o bem da vida humana e oferece uma possível resposta para a pergunta: "qual o melhor estilo de vida para um ser humano como eu?". Para o autor, mais do que uma resposta a nível individual, os bens da vida humana precisam estar integrados com os padrões gerais de uma tradição, e para isso Maclntyre desenvolve seu conceito de prática social.

$\mathrm{Na}$ estruturação de sua teoria moral, MacIntyre (2001) afirma que é no interior daquilo que ele chama de prática que as virtudes são exercidas. Para tanto, o significado de prática proposto é de

Qualquer forma coerente e complexa de atividade humana cooperativa, socialmente estabelecida, por meio da qual os bens internos a essa forma de atividade são realizados durante a tentativa de alcançar os padrões de excelência apropriados para tal forma de atividade, e parcialmente dela definidores, tendo como consequência a ampliação sistemática dos poderes humanos para alcançar tal excelência, e dos conceitos humanos dos fins e dos bens envolvidos (Maclntyre, 2001, p. 316)

O autor oferece exemplos e contraexemplos, como no caso da agricultura, que pode ser considerada uma prática, enquanto o ato de plantar um vegetal, não. No mesmo sentido, o jogo da velha ou jogar uma bola com habilidade não são exemplos de prática, mas o jogo de futebol sim. Em outros momentos, menciona que os esportes também são exemplos de práticas no sentido proposto pela sua teoria.

Para esclarecer, Maclntyre (2001) elenca as características necessárias para que algo seja uma prática. A primeira é a presença de bens internos. $\mathrm{O}$ autor

\footnotetext{
1 Na Filosofia Grega clássica, virtude é uma das traduções do termo grego areté, que representa o modo excelente de agir. Segundo Abbagnano (2012), a definição de virtude dada por Aristóteles é a mais difundida na ética clássica, relacionando questões que perpassam as ações e o entendimento.
} 
ilustra com uma situação hipotética de ensino de xadrez a uma criança. No início, ela não tem interesse no jogo. Assim, realiza-se um acordo: se ela jogar, receberá uma quantidade de doces e, se vencer a partida, ganhará uma quantidade extra. Jogando só pela recompensa externa, a criança encontra-se motivada somente pelos doces. Por outro lado, espera-se que em um determinado momento ela encontre

Nos bens específicos do xadrez, na aquisição de certa capacidade analítica especialíssima, imaginação estratégica e intensidade competitiva, um novo conjunto de razões, e razões agora não apenas para vencer em determinada ocasião, mas para tentar destacar-se de todos os modos que o jogo de xadrez exigir. (Maclntyre, 2001, p. 317).

Segundo o autor, os bens internos de uma prática podem ser reconhecidos somente ao participar da prática em questão ou de outra semelhante. Porém, há os bens externos, que são contingentes e relacionados à prática de modo acidental, como os doces no exemplo do xadrez e, em outras práticas, o dinheiro, o status, a fama, etc. Os bens externos podem ser alcançados de diversas formas que não apenas realizando a prática em questão.

Para Maclntyre (2001, p. 320), os bens externos, “[...] quando conquistados, sempre são de propriedade e posse de alguém, além disso, são tais que quanto mais se tem, menos há para outras pessoas". São recursos limitados e finitos, estando em concorrência para que sejam obtidos, como no caso do dinheiro e do poder. Já a disputa dos bens internos envolve a busca pela excelência e, quando conquistados, beneficiam toda a comunidade envolvida na prática. Maclntyre (2001) cita o caso do jogador William Gilbert Grace, que aprimorou o manejo do taco de críquete de modo inovador. A realização enriqueceu a toda a comunidade do esporte, que se beneficiou de uma excelência.

Portanto, o autor ressalta aquilo que não é uma prática, como o caso de um conjunto de capacitações técnicas, mesmo que tenham um objetivo unificado e que seu exercício possa ser valorizado ou apreciado por si mesmo. Certas capacidades técnicas podem compor uma prática e serem utilizadas por ela, contudo, não são suficientes para caracterizá-la.

A segunda característica necessária das práticas, para Maclntyre (2001), é que elas se enriquecem e se transformam através da busca humana pela excelência e bens internos, que se desenrola ao longo da história. Isso dá à prática sua própria história, diferente da história do aprimoramento de uma habilidade técnica isolada. Disso resulta que, ao realizarmos uma prática, além de nos relacionarmos com as pessoas que participam da comunidade, também nos relacionamos com os que nos precederam, com destaque para quem, de algum modo, ampliou os padrões de excelência e a própria prática.

Nesse sentido, toda prática possui uma história, que também é a história de sua comunidade, além dos padrões de excelência que foram construídos, definindo-a. E, quando ingressamos nela, é preciso reconhecer esses padrões. Isso não implica que os padrões de excelência estão imunes a críticas, contudo, o ingressante na prática aprenderá as formas ótimas encontradas pelos participantes que o precederam, e então poderá, na competição pelos bens internos, criar novos padrões.

Para ilustrar o ponto, novamente Maclntyre (2001, p. 320) cita o esporte e afirma que "[...] se, ao começar a jogar beisebol, eu não aceitar que os outros sabem melhor que eu quando se deve jogar uma bola de efeito e quando não jogar, jamais aprenderei a admirar o bom arremesso, muito menos arremessar".

Esse desenvolvimento do conceito de prática social é a base da teoria das virtudes de Maclntyre. Para ele, "[...] a virtude é uma qualidade humana adquirida, cuja posse e exercício costuma nos capacitar a alcançar aqueles bens internos à prática e sua ausência nos impede para todos os efeitos, de alcançar tais bens" (Maclntyre, 2001, p. 321). Além disso, como foi possível identificar, toda prática envolve o relacionamento com as pessoas que dela participam, sendo as virtudes referências definidoras desse relacionamento.

Pode-se verificar algumas reflexões que surgiram na Filosofia do Esporte a partir da concepção de Maclntyre. Como destaca McFee (2004), há modos diferentes pelos quais a Filosofia do Esporte recruta as ideias do autor, com aceitação integral, parcial ou mesmo refutação. Contudo, dado o escopo deste texto, serão apresentadas de forma breve algumas dessas apropriações.

Uma das contribuições de Maclntyre para a Filosofia do Esporte é abordada por McFee (2004), que analisa como as práticas definem as escolhas dos praticantes. Segundo o autor, a prática opera normativamente sobre o modo como deliberamos, uma vez que o padrão da prática é parte definidora dela. Além disso, ingressar nela acarreta aceitar seus padrões. Em outras palavras, ingressar em uma prática "[...] é sujeitar minhas próprias atitudes, opções, preferências e gostos aos padrões que definem a prática [...]" (Maclntyre, 2001, p. 320).

A partir disso, McFee (2004) menciona a natureza comunitária da prática, destacando que além das regras dela própria, há o desenvolvimento de um ethos do esporte, com um modo próprio operado dentro dele e de sua comunidade.

Em contrapartida, ao analisarem o esporte como prática social, Butcher e Schneider (1998) afirmam que a aceitação dos padrões de excelência não significa uma obediência inquestionável, pois as mudanças acontecem dentro da própria prática e operam no contexto formado pela tradição. Além disso, segundo eles, as práticas criam oportunidade de adquirir e expandir bens e desenvolver concepções de valores aplicáveis em nossas vidas.

Ainda sobre o aspecto comunitário, Reid (2012) afirma que uma das principais contribuições da teoria da prática social aplicada ao esporte é que uma das formas 
de adquirirmos as virtudes é através do esporte, e que o mais importante não é o treinamento ou a performance, mas sim a participação ativa na comunidade da prática, que envolve pessoas, histórias e padrões de excelência compartilhados. Desse modo, para a autora, as práticas não devem ser meramente um agrupamento de indivíduos que compartilham habilidades técnicas, mas sim um grupo unido por valores compartilhados. Para ela, a teoria da prática social faz-se importante para nos lembrar da primazia da comunidade em contraposição à tendência moderna da individualidade.

Reid (2012) retoma os conceitos de bens internos e externos para relacioná-los com questões esportivas, posto que a ênfase equivocada nos bens externos pode levar a sérios problemas, entre eles o doping. Por outro lado, a autora pondera que proibindo substâncias e tecnologias que melhoram o desempenho pode-se impedir os indivíduos não apenas de alcançar bens externos, mas também os internos, adquiridos por meios da participação que, sem esses recursos, talvez não fosse possível. Sendo assim, ela argumenta que a distinção entre bens internos e externos por vezes pode ser muito rígida, e que alguns bens e situações podem não ser claramente definidos dentro desses parâmetros.

Outra contribuição significativa da teoria de Maclntyre é abordada por López Frías (2015), para o qual compreender o esporte como prática social, com bens internos que podem ser especificados apenas dentro dela própria, implica que ele possua um grau significativo de autonomia em relação à sociedade e um conjunto próprio de valores que podem se contrapor a valores dominantes. Contudo, o autor defende que a noção de esporte como prática social é adequada apenas para atividades físico-competitivas de acordo com o ideal amador, pois apenas este assume o desafio do jogo como um fim em si mesmo, superando outros objetivos, como os bens externos.

López Frías (2015) também apresenta algumas limitações da teoria de Maclntyre. Segundo o autor, a criação do paradigma internalista e externalista é consequência da recepção do trabalho de Maclntyre e, muitas vezes, o esporte pode ser concebido de modo mais amplo, sem necessariamente estar atrelado a esse dualismo, pois pode atender a uma série de valores inerentes das práticas esportivas. Outro ponto sensível é identificado por McFee (2004), ao considerar que a definição de MacIntyre sobre aquilo que é ou não é uma prática social pode não ser totalmente clara, sendo possível contestar se o esporte pode ser caracterizado como tal.

Desse modo, o conceito de prática de MacIntyre (2001), quando operado pela Filosofia do Esporte, pode ser um modo de investigar as questões próprias do esporte, seja pela dualidade entre bens internos e externos, as relações entre os membros de uma comunidade de praticantes, o papel das virtudes, as tensões entre a tradição e os padrões de excelência de uma prática, entre outros. Ainda pouco explorado quando relacionado ao esporte no Brasil, o conceito apresenta-se como uma oportunidade de debate, tanto pelas suas possíveis contribuições como por suas limitações.

\section{CONSIDERAÇÕES FINAIS}

A partir das reflexões deste texto, pode-se verificar que o entendimento do esporte e dos demais conteúdos da Educação Física como prática social, no sentido proposto por MacIntyre, pode apresentar diversas contribuições e também limitações, inclusive à luz do diálogo com a já estabelecida noção de práticas corporais.

É possível citar, por exemplo, que a definição de Maclntyre ocasiona que os esportes e conteúdos relacionados possuem valor em si mesmos com seus respectivos bens internos, o que possibilita a investigação aprofundada sobre tais bens. Disso decorre a busca pelos padrões de excelência, algo extremamente caro no meio esportivo. Esses padrões, por sua vez, beneficiam uma comunidade de praticantes, que possui uma história e um conjunto de tradições.

Portanto, em sentido ontológico, como premissa da definição de prática social, abre-se a possibilidade de aprofundar-se em questões sobre o relacionamento dos praticantes com a própria prática, sua história, seus bens internos e externos. Dentre esses bens estão a normatização das escolhas e o ethos proporcionado com a criação de cultura própria de um conjunto de pessoas envolvidas na prática, as tensões criadas pelos padrões de excelência no interior da comunidade, além da discussão sobre a virtude, ou seja, um modo de ser e agir no esporte que pode ser transposto para outras áreas da vida.

Por outro lado, ainda sobre as contribuições de Maclntyre, sua definição excluiria alguns conteúdos da Educação Física que não possuem as características necessárias para serem considerados práticas sociais. É possível também que outros conteúdos fiquem em uma área incerta. Comparativamente, tais questões não se colocam no uso do conceito de prática corporal pois, ainda que menos estabilizado, oferece por princípio uma maior amplitude de significantes.

Em relação aos distanciamentos entre os conceitos, pode-se citar, primeiramente, a distinção em como os termos foram pensados inicialmente. $O$ de práticas corporais foi desenvolvido tendo em vista a Educação Física e seus conteúdos, enquanto o termo proposto por Maclntyre foi pensado para o contexto de uma teoria filosófica e, posteriormente, utilizado pela Filosofia do Esporte para refletir sobre seus conteúdos.

É possível vislumbrar uma maior estabilidade do termo proposto por Maclntyre, uma vez que visa sustentar uma teoria moral, enquanto o conceito de práticas corporais pode não apresentar uma definição precisa ou, de fato, ser de difícil estabilização, dada a heterogeneidade de seus usos e a amplitude de significantes que o caracteriza. 
Por outro lado, também existem proximidades entre os termos, pois ambos ressaltam o papel da cultura (mesmo que por vias distintas) e tratam a prática de maneira não isolada, contextualizando-a na história e problematizando como os sujeitos nela se inserem e a realizam.

Assim sendo, os caminhos aqui traçados não apresentam soluções definitivas, mas apontam potencialidades a serem exploradas, tanto na ampliação do debate sobre o termo práticas corporais como no aprofundamento das questões da Filosofia do Esporte sobre o pensamento de Alasdair MacIntyre. Ressalta-se ainda que, dada a própria riqueza de como a palavra prática é recrutada na Educação Física, não foi possível contemplar aqui toda a polissemia do termo. Contudo, espera-se que este texto contribua para demonstrar seus diversos usos no contexto da Educação Física.

\section{FINANCIAMENTO}

O presente trabalho não contou com apoio financeiro de nenhuma natureza para sua realização.

\section{CONFLITOS DE INTERESSE} interesse.

Os autores declaram não haver conflitos de

\section{REFERÊNCIAS}

Abbagnano N. Dicionário de filosofia. 6. ed. São Paulo: WMF Martins Fontes; 2012.

Betti M. Educação Física como prática científica e prática pedagógica: reflexões à luz da filosofia da ciência. Rev Bras Educ Fís Esporte. 2005;19(3):183-97. http://dx.doi. org/10.1590/S1807-55092005000300002.

Betti M. Por uma teoria da prática. Motus Corporis. 1996;3(2):73-127.

Boccati PA. Notas sobre a Ética de Alasdair Maclntyre no Campo da Filosofia do Esporte (Dissertação de Mestrado). Campinas: Faculdade de Educação Física, Universidade Estadual de Campinas; 2020.

Butcher R, Schneider A. Fair play as respect for the game. J Philos Sport. 1998;25(1):1-22. http://dx.doi.org/10.1080 /00948705.1998.9714565.
Coletivo de Autores. Metodologia do Ensino de Educação Física. São Paulo: Cortez; 1992. Coleção Magistério. $2^{\circ} \mathrm{Grau}$. Série Formação do Professor.

Devine JW, Lopez Frías FJ. Philosophy of sport. In: Zalta EN. The Stanford Encyclopedia of Philosophy (Fall 2020 Edition) [Internet]. 2020 [citado 2021 Set 7]. Disponível em: https:// plato.stanford.edu/archives/fall2020/entries/sport

Lazzarotti A Fo, Silva AM, Antunes PC, Silva APS, Leite JO. O termo práticas corporais na literatura científica brasileira e sua repercussão no campo da Educação Física. Movimento. 2010;16(1):11-29. http://dx.doi.org/10.22456/19828918.9000.

López Frías FJ. El impacto de Tras la Virtud de Alasdair Maclntyre en la filosofía del deporte: los equívocos del paradigma internalista. Cuad Salmant de Filos. 2015;42:179-202. http://dx.doi.org/10.36576/summa.39716.

Maclntyre A. Depois da virtude: um estudo da teoria moral. Bauru: EDUSC; 2001.

McFee G. Normativity, justification and (Maclntyrean) practices: some thoughts on methodology for the Philosophy of Sport. J Philos Sport. 2004;31(1):15-33. http://dx.doi.org /10.1080/00948705.2004.9714646.

Reid $\mathrm{H}$. Introduction to the philosophy of sport. United Kingdom: Rowman \& Littlefield Publishers; 2012.

Silva AM, Damiani IR. As práticas corporais na contemporaneidade: pressupostos de um campo de pesquisa e intervenção social. In: Silva AM, Damiani IR. Práticas corporais: gênese de um movimento investigativo em educação física. Vol. 1. Florianópolis: Nauemblu Ciência \& Arte; 2005

Silva AM, Lazarotti Filho A, Antunes PC. Práticas corporais. In: González FJ, Fensterseifer PE. Dicionário crítico de Educação Física. Ijuí: Ed. Unijuí; 2014.

Silva AM. Entre o corpo e as práticas corporais. Arq Mov. [Internet]. 2014 [acesso em 29 de agosto de 2021];10(1):520. Disponível em: https://revistas.ufrj.br/index.php/am/ article/view/9228

Soares CL. Práticas corporais: invenção de pedagogias? In: Silva AM, Damiani IR. Práticas corporais: gênese de um movimento investigativo em educação física. Vol. 1. Florianópolis: Nauemblu Ciência \& Arte; 2005. 